Chapman University

Chapman University Digital Commons

Physical Therapy Faculty Articles and Research

Physical Therapy

5-28-2016

\title{
How Should We Teach Lumbar Manipulation? A Consensus Study
}

Michael O'Donnell

University of Southern California

Jo Armour Smith

Chapman University, josmith@chapman.edu

Alex Abzug

cPaulseth and Associates Physical Therapy

Kornelia Kulig

University of Southern California

Follow this and additional works at: http://digitalcommons.chapman.edu/pt_articles

Part of the Musculoskeletal System Commons, and the Physical Therapy Commons

\section{Recommended Citation}

O’Donnell M, Smith JA, Abzug A, Kulig K. How should we teach lumbar manipulation? A consensus study. Manual Therapy. 2016;25:1-10. doi: 10.1016/j.math.2016.05.003.

This Article is brought to you for free and open access by the Physical Therapy at Chapman University Digital Commons. It has been accepted for inclusion in Physical Therapy Faculty Articles and Research by an authorized administrator of Chapman University Digital Commons. For more

information, please contact laughtin@chapman.edu. 


\section{How Should We Teach Lumbar Manipulation? A Consensus Study}

\section{Comments}

NOTICE: this is the author's version of a work that was accepted for publication in Manual Therapy. Changes resulting from the publishing process, such as peer review, editing, corrections, structural formatting, and other quality control mechanisms may not be reflected in this document. Changes may have been made to this work since it was submitted for publication. A definitive version was subsequently published in Manual Therapy, volume 25, in 2016. DOI: 10.1016/j.math.2016.05.003

The Creative Commons license below applies only to this version of the article.

\section{Creative Commons License}

\section{(c) $(i) \Theta($ )}

This work is licensed under a Creative Commons Attribution-Noncommercial-No Derivative Works 4.0 License.

\section{Copyright}

Elsevier 


\section{Accepted Manuscript}

How should we teach lumbar manipulation? A consensus study

Michael O'Donnell, Jo Armour Smith, Alex Abzug, Kornelia Kulig

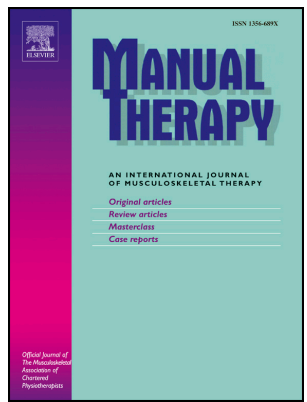

PII:

S1356-689X(16)30028-5

DOI:

10.1016/j.math.2016.05.003

Reference: $\quad$ YMATH 1855

To appear in: Manual Therapy

Received Date: 5 February 2016

Revised Date: 16 May 2016

Accepted Date: 20 May 2016

Please cite this article as: O'Donnell M, Smith JA, Abzug A, Kulig K, How should we teach lumbar manipulation? A consensus study, Manual Therapy (2016), doi: 10.1016/j.math.2016.05.003.

This is a PDF file of an unedited manuscript that has been accepted for publication. As a service to our customers we are providing this early version of the manuscript. The manuscript will undergo copyediting, typesetting, and review of the resulting proof before it is published in its final form. Please note that during the production process errors may be discovered which could affect the content, and all legal disclaimers that apply to the journal pertain. 


\title{
HOW SHOULD WE TEACH LUMBAR MANIPULATION? A CONSENSUS STUDY
}

\author{
Michael O’Donnell ${ }^{\mathrm{a}}$, Jo Armour Smith ${ }^{\mathrm{a}, \mathrm{b}}$, Alex Abzug ${ }^{\mathrm{c}}, \mathrm{K}^{\mathrm{K}}$ ornelia Kulig ${ }^{\mathrm{a}}$
}

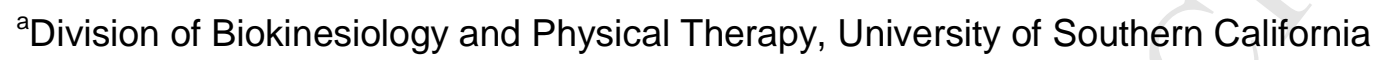

University of Southern California

1540 East Alcazar Street, CHP-155

Los Angeles, CA 90089

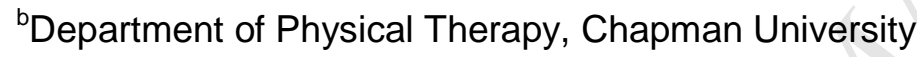

'Paulseth and Associates Physical Therapy, Los Angeles, California

Corresponding author: Jo Armour Smith, josmith@chapman.edu 
HOW SHOULD WE TEACH LUMBAR MANIPULATION? A CONSENSUS STUDY 


\section{ABSTRACT}

\section{Background}

Spinal manipulation is an effective intervention for low back pain, yet there is little consistency in how this skill is taught.

\section{Objectives}

The purpose of this study was to identify what educators and clinicians believe are important characteristics of the patient and operator position prior to side-lying lumbar manipulation and the patient position and operator motion during the manipulative thrust.

\section{Design}

A multi-disciplinary correspondence-based Delphi method

\section{Methods}

Three rounds of questionnaires were sent to physical therapists, osteopaths and chiropractors. Consensus was established in Round 3 if at least $75 \%$ of respondents identified a characteristic as very important/extremely important on a 5-point Likert scale.

\section{Results}

265 educators and clinicians completed the three rounds of questioning. There was consensus that localization to target segment, patient comfort, table height, and log rolling the patient towards the operator are important characteristics of patient position during the preparatory phase. During the manipulation phase, respondents agreed that it is important to maintain localization to the segment and rotate the patient's pelvis and lumbar spine. For the operator characteristics, consensus was reached for the following 
items; moving up and over the patient, maintaining contact using forearms, and close contact between the operator and patient (preparatory phase); generating force through the body and legs, dropping the body downwards, maintaining localization, and providing a high-velocity and low-amplitude thrust (manipulation phase).

\section{Conclusions}

This Delphi study successfully identified key characteristics of patient position and operator position and motion for effective delivery of side-lying lumbar spine manipulations. 
Keywords:

Spinal manipulative therapy, lumbar spine, manual therapy, Delphi, education 


\section{INTRODUCTION}

Low back pain is a major healthcare problem in Western societies, with enormous costs in terms of healthcare expenditures and productivity as well individual pain and suffering. There are very few interventions that have demonstrated significant effectiveness beyond the natural resolution of symptoms that can be attributed to the passing of time. ${ }^{1}$ However, research suggests that spinal manipulative therapy (SMT) reduces pain and disability in individuals with back pain. ${ }^{2-4}$ Manipulation is performed by clinicians in several disciplines, including physical therapists, osteopaths and chiropractors. Spinal manipulation can be defined as "the application of rapid movement to vertebral segments producing joint surface separation, transient sensory afferent input and reduction in perception of pain. Joint surface separation will commonly result in intra-articular cavitation that, in turn, is commonly accompanied with an audible pop" ${ }^{5}$ Lumbar manipulation is often performed with the patient in side-lying (Figure 1). The rotatory side-lying lumbar manipulation is a complex motor skill that requires substantial training and practice by the novice clinician to deliver proficiently and effectively.

Much of the current research investigating SMT focuses on what is happening at the patient-operator interface, without consideration of the operator's mechanics. ${ }^{6,7-13}$ Existing research has also quantified the differences in magnitude, duration and direction of force at the patient-operator interface between novice and expert clinicians performing SMT. ${ }^{7,8,13,14}$ Additionally, studies focusing on skill acquisition have provided novice operators with different methods of instruction to determine which method results in the best learning of the skill. ${ }^{9-11}$ However, much of the existing information that 
considers how the operator should perform manipulative techniques is based on individual expert opinion. There are multiple texts that describe how to perform SMT. ${ }^{15-}$ ${ }^{21}$ These texts elaborate on the specifics of patient positioning, how to achieve an adequate pre-manipulative barrier or "pre-load", and the hand and body position of the practitioner. In short, they capture static positioning but do not describe how practitioners then move their body to generate the appropriate force at the patientoperator interface. Similarly, Sizer et al., (2007) $)^{22}$ conducted a Delphi study of physical therapy educators to determine the critical skill-sets required for competency in manual therapy. From the Delphi survey and factor analysis the authors distilled eight essential skill-sets. Only one of the eight skills addressed the issue of force generation and no specific description was provided of how the practitioners should position themselves, shift their weight or develop their body's momentum in order to generate the forces needed to produce an effective manipulation.

As a result of the substantial evidence for the effectiveness of manipulation for spinal conditions, the use of manipulation for lumbar spine conditions is recommended internationally in a number of clinical practice guidelines. ${ }^{23-25}$ Additionally, instruction in manipulation has been included in entry level physical therapy curricula in the United States since $2009^{26}$ and is now required for program accreditation in North America. ${ }^{27,28}$ Therefore it is important that practitioners are taught how to perform these techniques proficiently, and that educators understand how best to teach them. A first step towards this goal is to determine the essential components of patient positioning and operator positioning during rotatory side-lying lumbar manipulation. Therefore, the 
purpose of this study was to identify what educators and clinicians believe to be the important characteristics of the patient and operator position prior to the rotary side-lying lumbar manipulation and the patient position and operator motion during the manipulative thrust.

\section{METHODS}

The classic Delphi method was chosen for this study because it is an established process for using informed opinion or expertise to develop a consensus where there is limited existing information. In this study design, three rounds of questioning or survey iterations are designed to develop a consensus of opinion concerning a specific topic. The first round is qualitative and designed to gather as wide a variety of opinions as possible whereas the second two rounds are quantitative. ${ }^{29}$ This approach has advantages over other survey methods. Specifically, participants remain anonymous and cannot be influenced by group pressure or more dominant individuals. ${ }^{30}$ Additionally, multiple rounds of questioning allow respondents to add additional insights and more thoroughly clarify the information developed by previous iterations. ${ }^{31}$

Round 1 of the survey included questions regarding the demographic information of the respondents. Additionally, there were four open-ended questions that asked the practitioners to identify the characteristics they believe to be important for teaching sidelying lumbar manipulation. They were: (1) patient position in the preparatory phase, (2) patient position in the manipulation phase, (2) operator position in the preparatory phase and (4) operator motion in the manipulation phase (see Appendix 1). This 
survey was sent via email to members of the American Academy of Orthopaedic Manual Physical Therapists (AAOMPT) and to individuals who were identified as teaching manual therapy or manipulative skills in entry-level DPT programs, chiropractic and osteopathy programs in the United States. The Institutional Review Body of XXXX approved the study.

Reponses from the open-ended questions in round 1 were manually compiled. A working group of three study investigators identified and codified themes from the qualitative responses. All three investigators have advanced training in manual therapy and are certified as Orthopaedic Clinical Specialists (OCS) by the American Board of Physical Therapy Specialties. The working group met on multiple occasions to review individual responses for each question. Initially, qualitative responses for each question containing similar word groupings or concepts were identified and the group defined an umbrella category for this concept (for example, individual responses regarding patient positioning such as "locked down to the proper level" or "positioning to isolated segment of interest" would be codified to the category "localization to target segment"). Each individual response was then codified to a category (or categories). The most highly represented categories in each question were then developed into descriptor statements that were further investigated in rounds 2 and 3.

Round 2 of the survey used Likert scales. The survey asked participants to quantify the relative importance of characteristics of patient position and operator position and motion that were identified in round one. Each characteristic was graded on a 5-point 
Likert scale anchored by the statements "Not at all important", "Very unimportant", "Neither important nor unimportant", "Very important", and "Extremely important". 32

Round 3 of the survey used exactly the same Likert items as round 2. In addition, for each item, participants were shown bar graphs of data demonstrating the results for the same item from round 2 . Therefore, round 3 provided participants with the opportunity to consider their response in the context of peer responses.

All rounds of the survey were implemented utilizing Qualtrics Research Suite software (Qualtrics, Provo, UT). Participants received an individual link to each survey via e-mail. If participants did not respond within two weeks of receiving the survey, they were sent a reminder e-mail. Results from rounds 2 and 3 of the survey were automatically collated by the Qualtrics software and then exported to Excel for additional analysis (Microsoft Excel 2010, Microsoft Corporation, Redmond, WA). For each item, the number of responses for "Not at all important" and "Very unimportant" were collated and categorized as "Unimportant", and the number of responses for "Very important" and "Extremely important" were collated and categorized as "Important". Consensus was established for each item if greater than $75 \%$ of participants identify the item as "Unimportant" or "Important". 22,33

\section{RESULTS}

\section{$\underline{\text { Respondents }}$}

\section{Round 1}


Our database of potential participants acquired manually from available institutional and organization webpages, consisted of 61 osteopathy faculty, 197 chiropractic faculty, 443 physical therapy faculty and 1867 members of the American Academy of Orthopaedic Manual Physical Therapists (AAOMPT). After removal of duplicates and invalid e-mail addresses, 2427 invitations to participate in the survey were e-mailed. Six hundred and twelve individuals completed round 1 of the survey ( $25 \%$ response rate). This initial sample included 571 physical therapists, 10 osteopaths and 31 chiropractors. On the whole, respondents were highly experienced clinicians, with the modal experience in the group being 15 years or more. Of the respondents to round $1,81 \%$ were currently teaching manipulation, either in a clinical or academic setting, or both.

\section{Rounds 2 \& 3}

Three hundred and sixty-five respondents completed round 2 of the survey, representing a $60 \%$ retention rate from round 1 . The round 3 survey was completed by 258 respondents $(71 \%$ retention rate from round $2 ; 11 \%$ overall response rate). The overall non-response rate from rounds 1 to 3 was similar across the three professions (physical therapists $42 \%$; osteopaths $40 \%$, chiropractors $39 \%$ ). Demographic data were missing for eleven individuals in this sample and were only partially completed by 40 others. Of the round 3 respondents, 193 reported holding a Doctor of Physical Therapy (DPT) or Master of Physical Therapy (MPT) degree, four were doctors of osteopathic medicine and 12 were doctors of chiropractic. Forty-nine individuals reported other or additional credentials, with 21 holding a Bachelor's degree in physical therapy, five holding a Master's degree other than MPT, eleven holding a Doctor of Science or 
Doctor of Health Science degree, and six holding a PhD. All but 14 of the respondents to round 3 had completed, or were completing, formal post-graduate training or certification. This post-graduate training primarily consisted of orthopedic residencies and fellowships, Orthopaedic Clinical Specialist certification, and certification or fellowship from AAOMPT and the North American Institute of Orthopaedic Manual Therapy. Additional characteristics of the round 3 respondents are presented in Table 1.

\section{Consensus results}

The responses to the round 3 survey are presented in Figures $\mathbf{2}$ and $\mathbf{3}$. Items that achieved a consensus during round 3 and were determined to be "Important" to the successful performance of the side lying lumbar manipulation are shown in Table 2. All of these items also achieved a consensus during round 2. One additional item achieved a consensus during round 2 but not during round 3 (importance of localization to the target segment with lumbar flexion/extension). There was no consensus on items that were "Unimportant" for the success of side lying lumbar manipulation. For those items that did not achieve consensus, the average (standard deviation) percentage of respondents identifying them as important was $44.5(0.11) \%$.

\section{DISCUSSION}

This investigation developed a consensus amongst educators and clinicians regarding the important aspects of teaching side-lying lumbar manipulation. Responses were obtained from a diverse cohort of respondents, many of whom had residency and/or 
fellowship training. We studied respondents' opinions regarding patient and operator position immediately prior to the manipulation, and the patient position and the operator motion during the manipulative thrust. A comparison between items in rounds 2 and 3 of the survey and recommendations in popular manual therapy texts is presented in Table 3.

For patient positioning both prior to and during the manipulation, respondents felt that localization to the chosen segment was important. During round 1 of the survey (open responses) participants did not specify whether the particular functional spinal unit (2 adjacent vertebrae, hereon termed "segment") was selected because it was symptomatic or had some form of motion limitation on clinical testing. However, these are the criteria commonly used to select a segment for manipulation. ${ }^{16,34-37}$ Despite this consensus that localization to a particular segment was important, respondents did not agree that the affected side should be uppermost, nor did they agree that one of the segment vertebrae should be aligned perpendicular to the table. Consensus was achieved in both the second and third rounds of the survey that rotation and side bending of the lumbar spine should be used to achieve localization. Several manual therapy authors describe the importance of localization. ${ }^{36,38}$ (Table 3) In this context, the term localization refers to the process of using combined movement (movement in three planes) so that application of a thrust can be focused on an isolated segment, in order to produce cavitation at that segment. This localization allows for optimal zygapophyseal joint pre-positioning, so that the manipulation can be achieved with a low amplitude motion. According to McCarthy $(2001)^{34}$ a high-velocity, low-amplitude 
thrust is applied in a position where the joint has reached the limit of movement in that particular combination of planar movements but is not at the end of available range for each of the movements if they were to be applied in isolation. In order to produce an end-of-combined-range position amenable to manipulative therapy, the combinations of movement used are often complex and appear to contradict the coupled movements of the spine. The use of these 'irregular' or non-coupled movements is thought to produce the 'lock' position in the adjacent joints commonly referred to in osteopathic literature. ${ }^{16}$ ${ }^{36}$ Flexion $^{39,40}$ and extension ${ }^{41}$ have been shown to influence the coupling of spinal segments. In the second round of the survey participants agreed that flexion or extension should also be used to achieve localization. Fewer respondents in the third round felt flexion and extension were important for localization and this did not achieve our a-priori threshold for consensus (71.8\%). Had we used a less stringent threshold criterion, this item would have achieved consensus. As localization using flexion/extension appears to be commonly advocated when teaching manipulation ${ }^{16,36,42}$ (Table 3) it is possible that the respondents felt that this aspect of localization was less important than rotation/side-bending, despite the biomechanical evidence. Additional studies will be needed to clarify how combinations of movement in all three planes may influence joint localization.

Although respondents felt that localization to a segment is important, some research shows manipulation may produce cavitation at segments other than the targeted segment. ${ }^{43-45}$ Additionally other authors report that the manipulation may be effective regardless of the side of manipulation. ${ }^{46}$ Further research will be needed to clarify to 
what extent localization to a specific segment and side of the spine is necessary for clinically effective manipulation. In particular, the distribution of some of the previously demonstrated neurophysiological effects of manipulation, such as hypoalgesia and muscle facilitation, may be regional rather than localized to the targeted segment. ${ }^{47}$ Interestingly, in spite of the agreement that localization to the segment is important, the respondents did not feel that it was essential for the operator to use their hands to palpate the desired segment. Therefore, localization must be achieved through a mechanism other than direct palpation. It is possible that operators can sense the localization by feeling the barrier (resistance to motion) using their forearms placed on the patient's trunk and pelvis.

Patient comfort was identified as being important in both the preparation and manipulation phase. This factor received a very high level of agreement. In the first round of our survey, in which participants responded to open-ended questions, many respondents felt that patient comfort was important yet very few respondents described what this entailed. Some respondents said the patient should be relaxed. Gibbons and Tehan $(2001)^{36}$ state that patient comfort is critical for achieving a successful SMT. Similarly, Maitland recommends oscillating the patient, without changing spinal position, in order to promote patient relaxation and comfort. ${ }^{18} \mathrm{It}$ is clear that non-verbal posture, body motion and prosody are also powerful means of communication. ${ }^{48}$ While not previously investigated in relation to manual therapy, we propose that patient comfort may also be influenced by the patient sensing the therapist's competence and confidence in performing the manipulative technique. 
Respondents agreed that optimal table height is important. In the first round some respondents described a specific metric for this position: the table height should be such that the operator's anterior superior iliac spine (ASIS) meets the patient's uppermost ASIS. This is taught by some manual therapy educators. ${ }^{16,36}$ However, it is interesting to note that in rounds 2 and 3 when respondents were asked specifically if the operator's pelvis should be at the same height as the patient's, consensus was not established. We can conclude that manual therapy educators and clinicians are in agreement that the treatment table should be at the optimal height, but that they do not all use anatomical landmarks on the operator and patient as a means of determining the proper height. This may reflect the limitation of using a Delphi method, in that there is an inability to further clarify or elaborate on responses in the second and third rounds of questioning.

Respondents noted that it is important to "logroll" the patient toward the operator prior to administering the manipulation. The general purpose of log-rolling is to maintain alignment of the whole spine while turning and moving a patient. ${ }^{49}$ Several manual therapy authors use the term logrolling when discussing SMT but do not define what they mean. ${ }^{17,21}$ Gibbons and Tehan $(2001)^{15}$ do not use the term logrolling but describe the "final minor adjustment" in which the patient is rolled $10-15^{\circ}$ toward the operator while maintaining the buildup of leverages (or localization) previously attained. Respondents concurred that during the manipulation phase, the operator should generate force by using their legs or body and by dropping their body downwards. 
Additionally, they also agreed that during the manipulation phase it is important to achieve rotation of the patient's pelvis and lumbar spine. Interestingly, there was no consensus that it was important for the operator to have their feet aligned in a particular direction or that it was important for the operator to maintain their trunk in vertical alignment. Presumably then, logrolling the patient allows the operator to achieve the rotation of the patient's pelvis or lumbar spine by dropping down once the patient is properly positioned.

Cook et al., $(2013)^{50}$ suggest that the clinical effects of forces imparted to joints during manipulation or mobilization may be independent of the velocity with which the force is applied. However, certain clinical characteristics may identify patient populations that respond more favorably to high-velocity manipulation than to low-velocity mobilization. ${ }^{51}$ Additionally laboratory studies investigating both the mechanical consequences of manipulation at the intra-articular surface ${ }^{45}$ and in the form of neurophysiological changes ${ }^{47,52}$ have described effects that only occur with a high-velocity thrust. The respondents in this study concluded that it was important that the force applied during the thrust is both high-velocity and low-amplitude (HVLA). While it may be implied that manipulation is a high-velocity and low-amplitude technique, some experts use the term manipulation in a more generic sense to encompass all types of manual therapy, including joint mobilization, soft tissue mobilization and thrust manipulation..$^{53}$ In the United States since 1998, the American Physical Therapy Association (APTA) Guide to Physical Therapist Practice has defined mobilization/manipulation as "a manual therapy technique comprised of a continuum of skilled passive movements that are applied at 
varying speeds and amplitudes, including a small amplitude/high velocity therapeutic movement." ${ }^{23}$ To achieve a common language for describing this area of the physical therapist's scope of practice, the terms "thrust" and "non-thrust" manipulation were established to replace the previous terms "manipulation" and "mobilization," respectively. The APTA Manipulation Education Manual for Physical Therapist Professional Degree Programs further defines thrust manipulation as a "high velocity, low amplitude therapeutic movement within or at the end range of motion" and nonthrust as manipulations that do not involve thrust. ${ }^{54}$ Thus, due in part to scope-ofpractice issues, several terms have been developed to describe the same type of procedure. Thrust manipulation, impulse, HVLA, spinal manipulative therapy (SMT) and grade $\mathrm{V}$ mobilization are all terms that have been used to describe the same type of manual procedures. Despite the ambiguity in the usage of the term manipulation, the respondents of this study concluded that high-velocity and low-amplitude forces were important characteristics of manipulation.

A Delphi approach was chosen for this study because it facilitates attaining a consensus when empirical evidence is lacking and when there are areas of uncertainty. ${ }^{55,56}$ This method is a time-effective means of obtaining a large number of opinions from a diverse sample of respondents without the potential problems of face-to-face committees or focus groups. During face-to-face consensus building, individuals may be inhibited from expressing opinions by more dominant or senior members of a group, and may be inordinately influenced by the group opinion. ${ }^{56,57}$ The Delphi method avoids these limitations by providing anonymity for respondents while still allowing them to consider 
their responses in the context of other expert opinion. However, the success of the Delphi process is entirely dependent upon having an appropriately sized and wellqualified panel of experts. ${ }^{55,56}$ One of the strengths of this study was the large sample size. The number of respondents in this study was significantly greater than that of similar Delphi surveys investigating physical therapy practice. 612 manual therapy educators and clinicians participated in the first round of our study and 258 remained by the final round. In contrast, the majority of previous studies have utilized expert panels with fewer than 100 individuals ${ }^{22,33,58,59,60}$ The overall response rate in the present study was also similar to or greater than comparable studies ${ }^{33,61,62}$ This study also benefited from a diverse and well-qualified panel of respondents. Manual therapy educators and clinicians from the fields of physical therapy, osteopathy and chiropractic participated. Although the number of osteopaths and chiropractors who participated in the study was smaller than that of physical therapists, the relative representation of each profession remained stable across the three rounds of the survey. This diversity of participants strengthens our results by including multiple professionals who routinely perform manipulation, ensuring a range of different perspectives. Having input from a multidisciplinary group of professionals delineates the common aspects of the technique that are considered, regardless of professional background. However, it should be noted that not all of the participants reported regularly using side-lying lumbar manipulation in their clinical practice.

There are some limitations inherent in using the Delphi approach. As in all Delphi studies, the round 1 survey, which frames the research question for the later rounds, 
was developed based on the investigators' experience and review of the literature. Additionally, the development of the second and third round of the survey was based upon the investigators' interpretation of the open, qualitative responses during round 1 . Although the investigators identified the primary categories of responses that encapsulated the vast majority of the open answers, in order to keep the round 2 and 3 surveys at a manageable length not all of the concepts in the open responses could be collated into Likert scales. Further, participants were unable to elaborate more on their responses during rounds 2 and 3 , resulting in some potential loss of information or additional viewpoints. Because the Delphi method requires individuals to respond to a series of questionnaires the retention rate of respondents across all rounds of the study is often low and this may impact generalizability of the results. However, the advantages of the Delphi method were that it facilitated investigating the opinions of a very large and diverse group of expert respondents from across the United States, with minimal expense.

\section{Conclusions}

This investigation is the first to develop a consensus amongst manual therapy educators and clinicians as to which characteristics are considered to be most important when teaching a side-lying lumbar spine manipulation. It is important that practitioners are taught how to perform these techniques competently. A first step towards this is to determine the essential components of patient positioning and operator application of this technique. These conclusions should be validated through biomechanical research as well as in studies contrasting expert and novice manual therapy practitioners. 
TABLES

Table 1. Characteristics of the round 3 respondents ${ }^{1}$ (SLM - side-lying lumbar manipulation)

CHARACTERISTICS

\section{NUMBER OF RESPONDENTS}

Years in clinical practice
$0-5$
25
$5-10$
48
$10-15$
43
$15-20$
43
$>20$
88

Source of manipulation training ${ }^{2}$

Didactic content in primary degree $\quad 104$

Practical content in primary degree $\quad 104$

Residency/fellowship 150

Continuing education 169

Practice setting ${ }^{3}$

Outpatient/ambulatory care 203

Hospital based facility 21

Inpatient acute care 2

Inpatient rehab care 1

Home health 1

Frequency of performing SLM ${ }^{4}$

Never/occasionally 30

$<1$ x per week 53

$1-3 \times$ per week 57

$4-6 \times$ per week 30

$6-9 \times$ per week $\quad 17$

$>10 \times$ per week 31

Setting of current SLM teaching

Academic 41

Clinical 71

Both academic and clinical $\quad 94$

Not currently teaching SLM $\quad 41$

\footnotetext{
${ }^{1} n=247$

${ }^{2}$ note that these categories are not mutually exclusive

${ }^{3} \mathrm{n}=228$

${ }^{4} \mathrm{n}=218$
} 
Table 2. Items achieving a consensus of being important to a successful side lying lumbar manipulation. For full text of each item please see Appendix 1.

ITEM

CONSENSUS

$(\%)^{1}$

Patient position - preparatory phase

Localization to target segment with rotation/side bend

83.5

Patient comfort

96.2

Table height

92.1

Log rolling patient towards operator

83.5

Patient position - manipulation phase

Maintain localization achieved during preparatory phase

89.4

Rotation of patient's pelvis and lumbar spine

88.6

Operator position - preparatory phase

Body up and over patient

93.1

Use of forearms to maintain contact/generate force

83.1

Close contact between operator and patient

98.5

Operator motion - manipulation phase

Generation of force through body and legs

92.3

Dropping downwards to generate force

82.2

Maintain localization while generating force

89.2

Thrust is high-velocity

96.9

Thrust is low-amplitude

87.2

${ }^{1}$ Percentage of participants identifying the item as Very Important or Extremely Important 
Table 3. Comparison between items in rounds 2 and 3 of the survey and recommendations in popular manual therapy texts

\begin{tabular}{|c|c|}
\hline Items in the Survey & Manual therapy texts \\
\hline Targeted segment uppermost (-) & $\begin{array}{l}\text { - No indication as to which side } \\
\text { should be uppermost } \\
\text { - Use algorithm to decide targeted } \\
\text { side (supine technique used) [(1) } \\
\text { positive side of standing flexion } \\
\text { test. (2) side of tenderness to } \\
\text { sacral sulcus. (3) patient-reported } \\
\text { most symptomatic side] }]^{46} \\
\text { - Uppermost side shall be the } \\
\text { symptomatic side }\end{array}$ \\
\hline Targeted segment perpendicular to table (-) & $\begin{array}{l}\text { During the localization procedure } \\
\text { the operator shall ensure that the } \\
\text { transverse processes of one the } \\
\text { segment vertebra remain } \\
\text { perpendicular to the table }\end{array}$ \\
\hline $\begin{array}{l}\text { Flex and extend to localize targeted } \\
\text { segment }(-)\end{array}$ & $\begin{array}{l}\text { The rationale for using neutral, } \\
\text { extended or flexed position should } \\
\text { be based on patient comfort } \\
\text { - Use the pelvis to flex and extend } \\
\text { the lumbar spine targeted segment } \\
\text { to find the midpoint (for a neutral } \\
\text { alignment) } \\
\text { - Use extension/flexion of the legs to } \\
\text { achieve further extension or flexion } \\
\text { in the lumbar spine } \\
\text { - Flex/extend the trunk to the point } \\
\text { that the upper segment begins to } \\
\text { move then flex/extend lower } \\
\text { extremities until the lower segment } \\
\text { moves }^{20}\end{array}$ \\
\hline Logroll (+) & $\begin{array}{l}\text { - Technique used to achieve } \\
\text { maximal relaxation of the patient } \\
\text { and to take up any remaining } \\
\text { slack }^{18} \\
\text { - Performed prior to inducing the } \\
\text { thrust as a means of creating } \\
\text { momentum as the technique is } \\
\text { better applied in a dynamic } \\
\text { position } \\
\text { - Last movement performed prior to } \\
\text { applying the thrust }{ }^{54}\end{array}$ \\
\hline
\end{tabular}




\begin{tabular}{|c|c|}
\hline Feet aligned in particular direction (-) & $\begin{array}{l}\text { Both feet are pointing towards the } \\
\text { head of the table }\end{array}$ \\
\hline Feel targeted segment (-) & $\begin{array}{l}\text { - Use finger tips between spinous } \\
\text { processes to assess for motion } \\
\text { while rotating the lumbar spine to } \\
\text { the target segment }{ }^{15,54} \\
\text { - Operator's hand monitors the } \\
\text { target segment as rotation is } \\
\text { introduced }^{20}\end{array}$ \\
\hline High velocity $(+) /$ low amplitude (+) & $\begin{array}{l}\text { - Must be rapid but not excessively } \\
\text { forceful }^{15}\end{array}$ \\
\hline $\begin{array}{l}\text { Localization to targeted segment with } \\
\text { rotation/side bend }(+)\end{array}$ & $\begin{array}{l}\text { - Use rotation from above if operator } \\
\text { desires to perform procedure in } \\
\text { further rotation } \\
\text { - A small amount of trunk rotation is } \\
\text { induced (not specific to the target } \\
\text { segment) }\end{array}$ \\
\hline
\end{tabular}

+ Delphi consensus was achieved

- Delphi consensus was not achieved 


\section{FIGURE LEGENDS}

Figure 1. Patient and operator position for the side-lying lumbar manipulation

Figure 2a. Items relating to patient position during the preparatory phase of a side-lying lumbar manipulation. Figure $\mathbf{2 b}$ Items relating to patient position during the manipulation phase of a side-lying lumbar manipulation.

Figure 3a. Items relating to operator position during the preparatory phase of the sidelying lumbar manipulation. Figure $\mathbf{3 b}$. Items relating to operator motion during the manipulation phase of the side-lying lumbar manipulation. 
FIGURES

Figure 1.

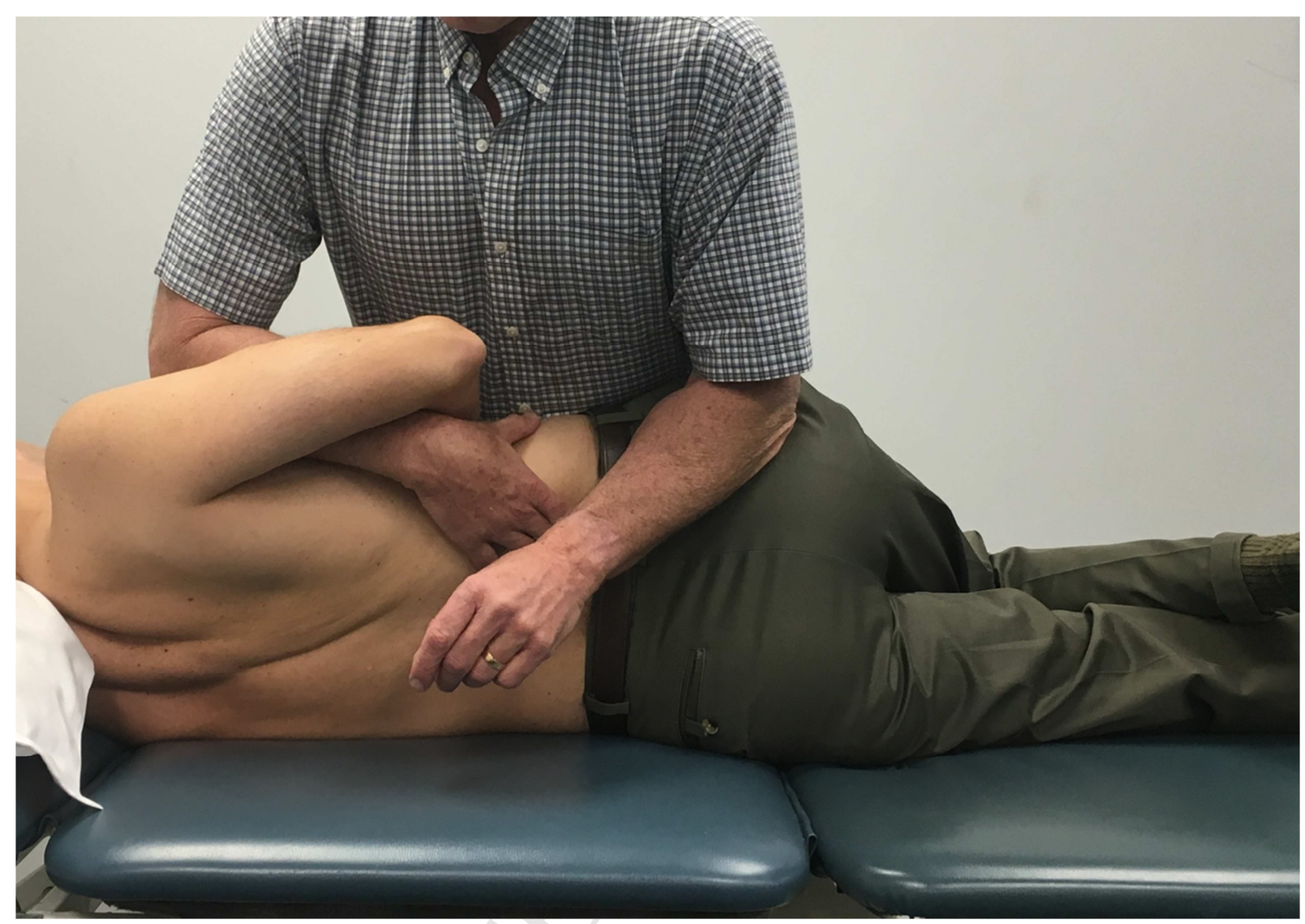




\section{Figure 2}
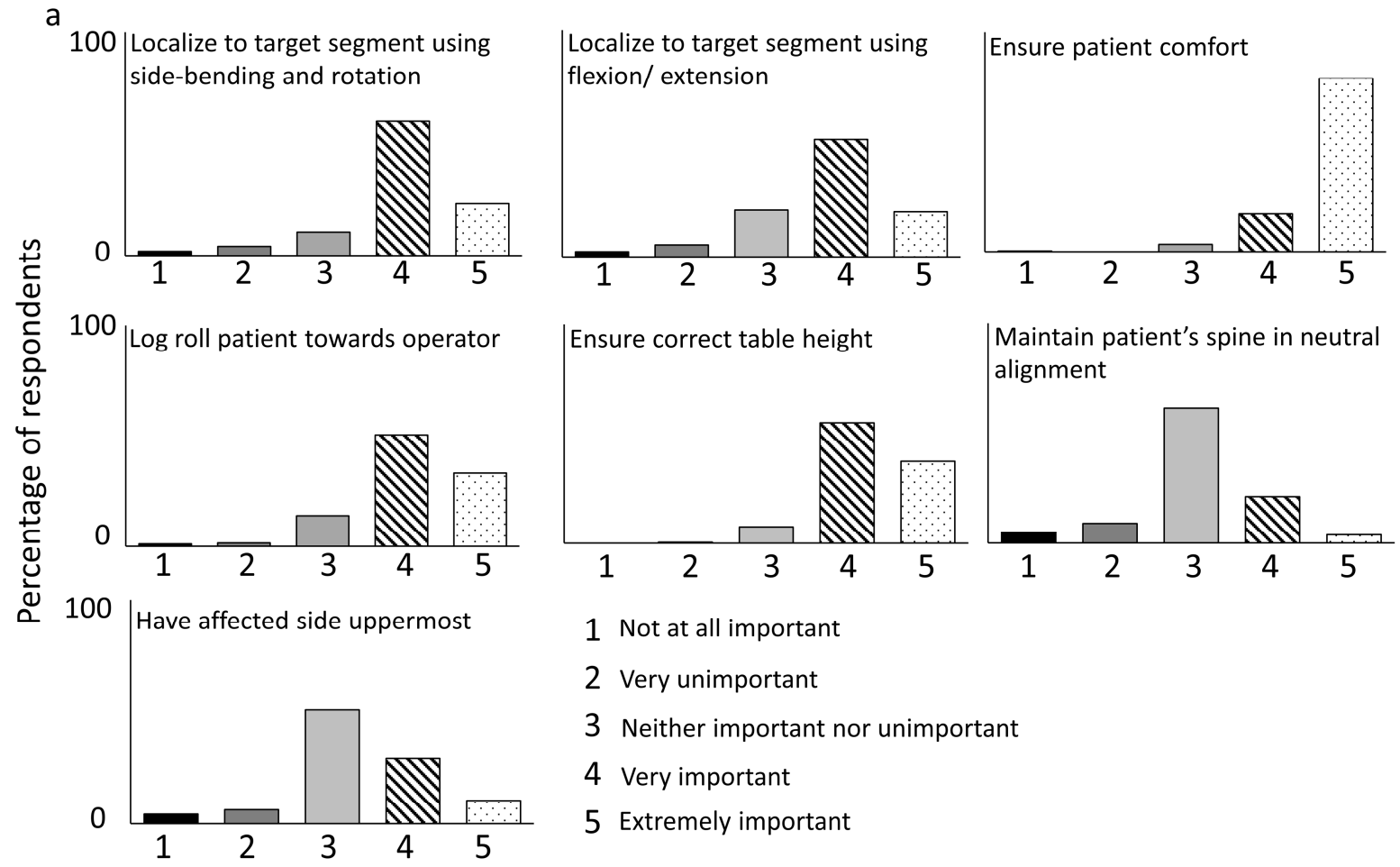

1 Not at all important

2 Very unimportant

3 Neither important nor unimportant

4 Very important

5 Extremely important
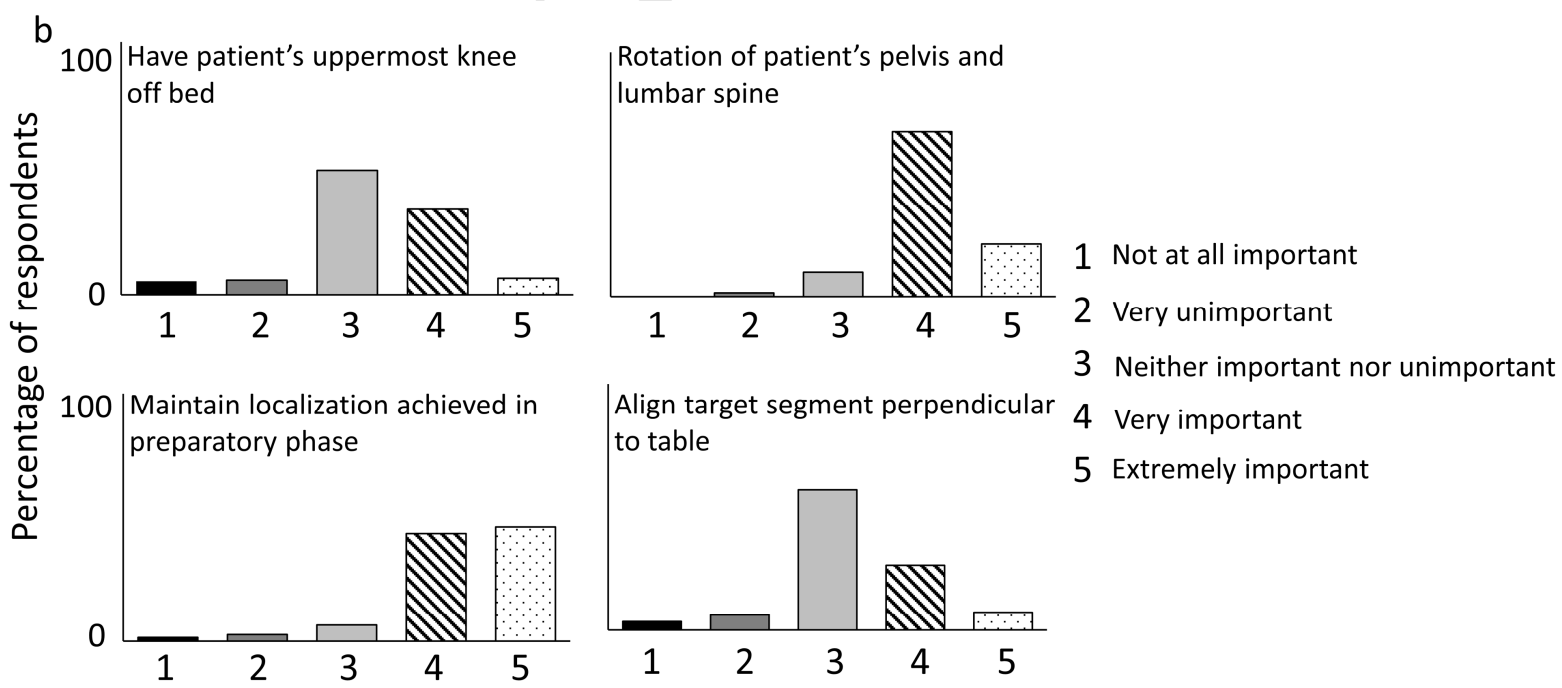
Figure 3.

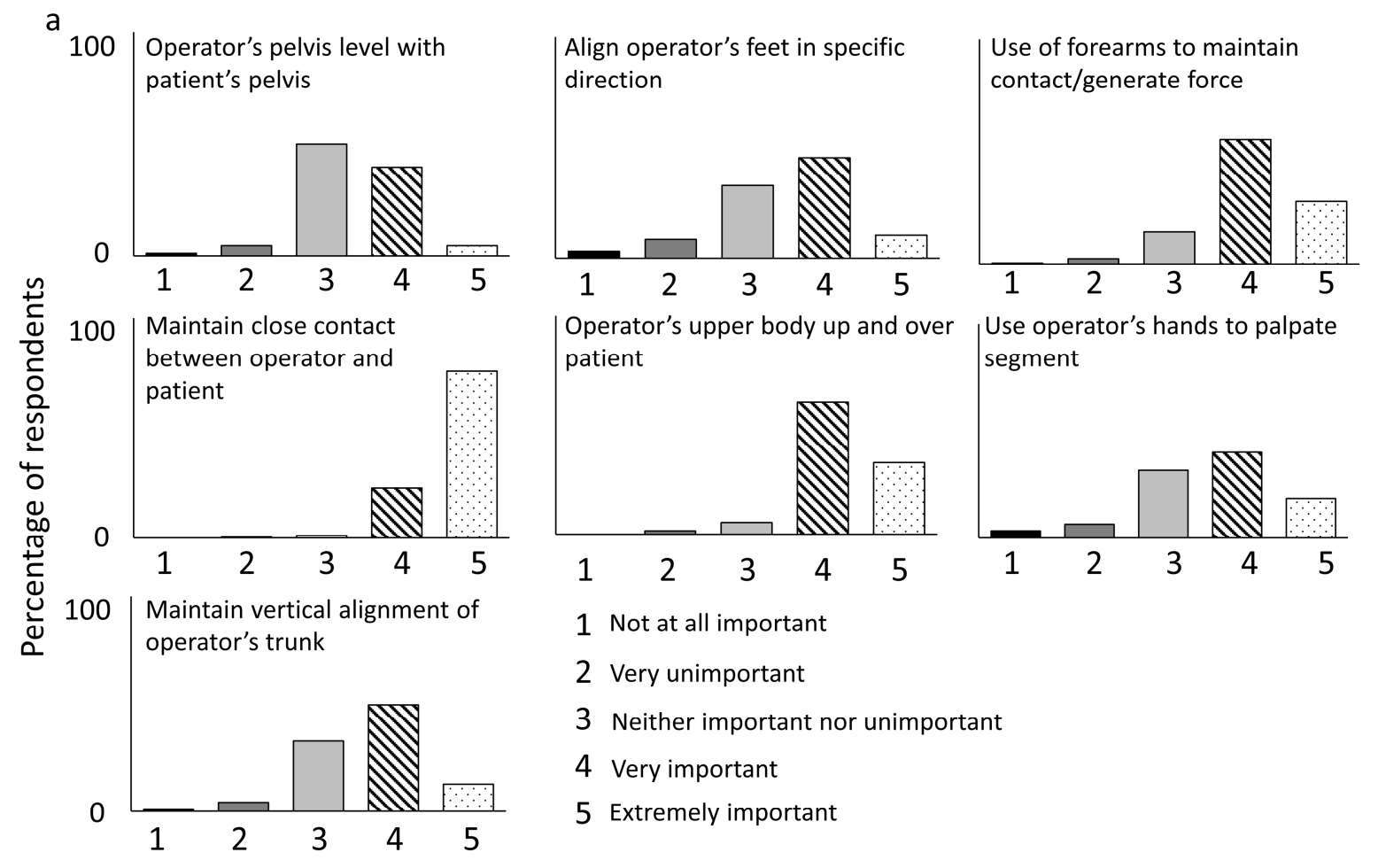




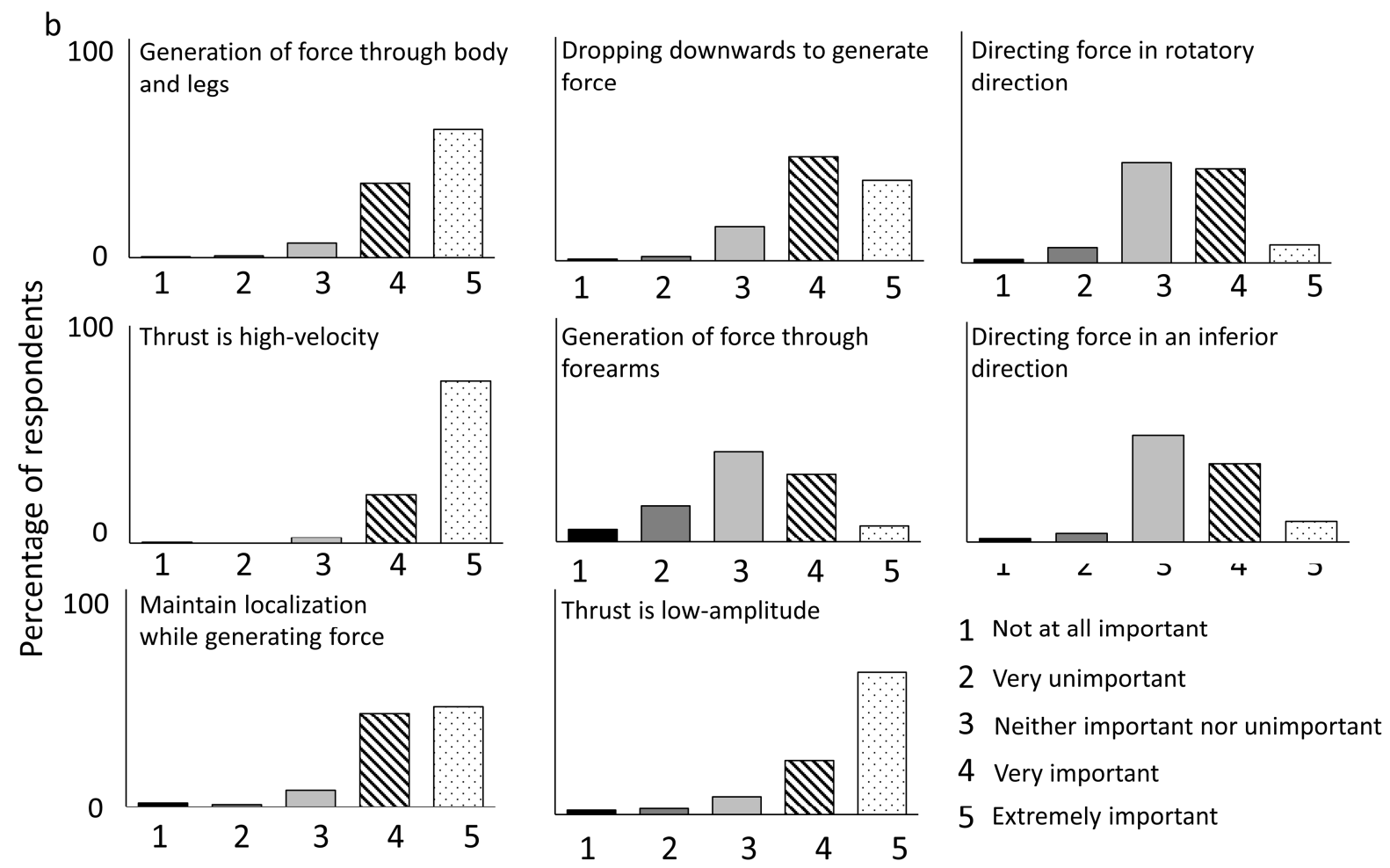

\section{APPENDIX 1}

\section{$\underline{\text { Round } 1 \text { open questions }}$}

Q1 - When teaching manual skills, what do you consider to be most important in the position of the patient during the preparatory phase of a side-lying lumbar manipulation? Q2 - When teaching manual skills, what do you consider to be most important in the position of the patient during the manipulation phase of a side-lying lumbar manipulation?

Q3 - When teaching manual skills, what do you consider to be most important in the position of the operator during the preparatory phase of a side-lying lumbar manipulation?

Q4 - When teaching manual skills, what do you consider to be most important in the motion of the operator during the manipulation phase of a side-lying lumbar manipulation? 
$\underline{\text { Rounds } 2 \text { and } 3 \text { Likert items }}$

In terms of patient position during the preparatory phase of a side-lying lumbar manipulation, how important is it to:

$\begin{array}{lllll}\text { Not at all } & \text { Very } & \text { Neither } & \text { Very } & \text { Extremely } \\ \text { Important } & \text { Unimportant } & \text { Important nor } & \text { Important } & \text { Important }\end{array}$

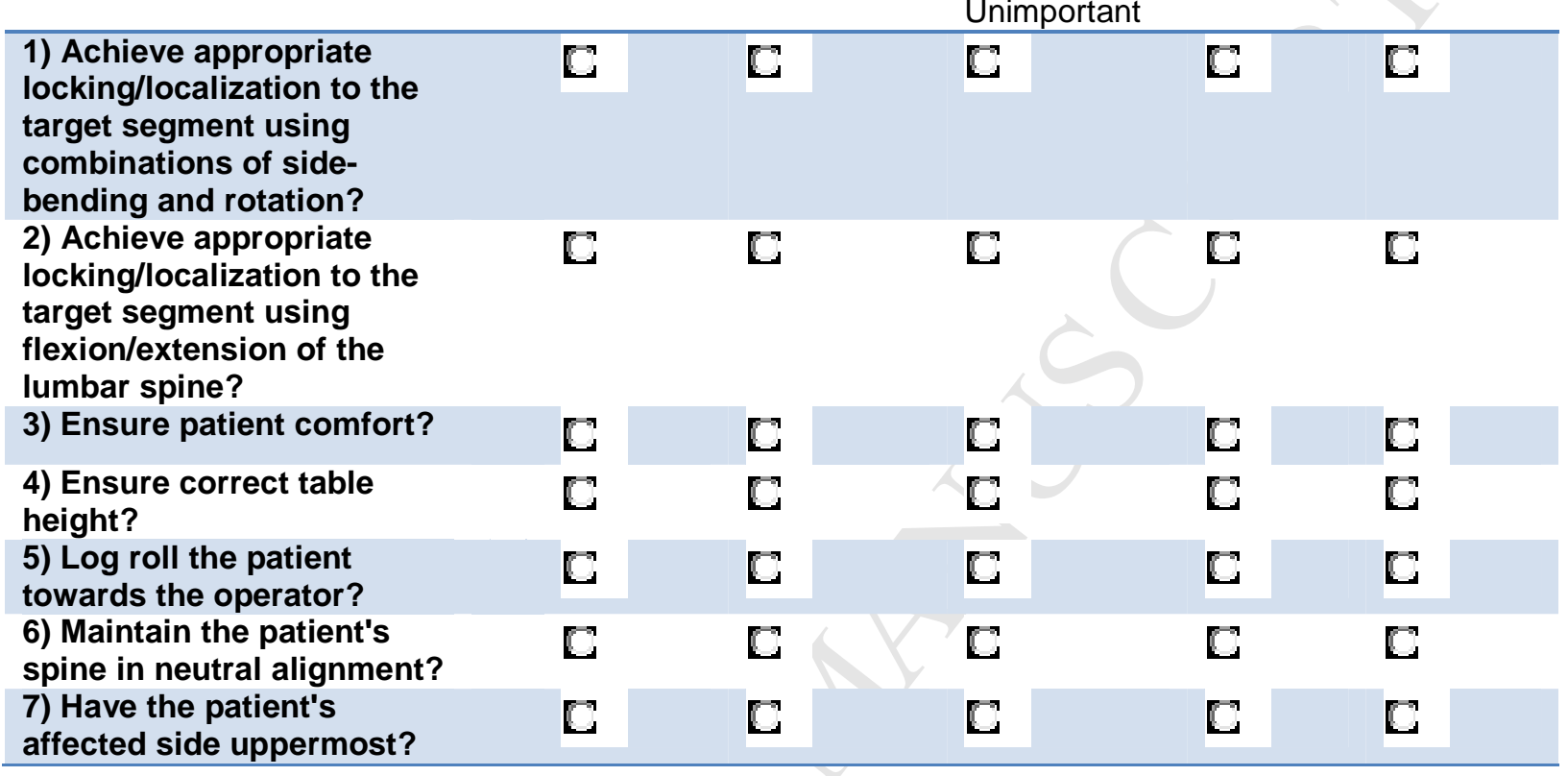

In terms of patient position during the manipulation phase of a side-lying lumbar manipulation, how important is it to:

$\begin{array}{lllll}\text { Not at all } & \text { Very } & \text { Neither } & \text { Very } & \text { Extremely } \\ \text { Important } & \text { Unimportant } & \begin{array}{l}\text { Important nor } \\ \text { Unimportant }\end{array} & \text { Important } & \text { Important } \\ & & & \end{array}$

\begin{tabular}{|c|c|c|c|c|c|}
\hline $\begin{array}{l}\text { 1) Have the patient's } \\
\text { uppermost knee off the } \\
\text { table? }\end{array}$ & $\mathrm{C}$ & C & $\mathrm{C}$ & $\mathrm{C}$ & $\mathrm{C}$ \\
\hline $\begin{array}{l}\text { 2) Maintain the } \\
\text { locking/localization to the } \\
\text { segment that was achieved } \\
\text { during the preparatory } \\
\text { phase? }\end{array}$ & $\mathrm{C}$ & $\mathrm{C}$ & $\mathrm{C}$ & $\mathrm{C}$ & $\mathrm{C}$ \\
\hline $\begin{array}{l}\text { 3) Achieve rotation of the } \\
\text { patient's pelvis and lower } \\
\text { lumbar spine? }\end{array}$ & C & $\mathrm{C}$ & $\mathrm{C}$ & $C$ & $C$ \\
\hline $\begin{array}{l}\text { 4) Align the target segment } \\
\text { perpendicular to the table? }\end{array}$ & $\mathrm{C}$ & $\mathrm{C}$ & $\mathrm{C}$ & $\mathrm{C}$ & $\mathrm{C}$ \\
\hline
\end{tabular}


In terms of operator position during the preparatory phase of a side-lying lumbar manipulation, how important is it to:

\begin{tabular}{|c|c|c|c|c|c|}
\hline & $\begin{array}{l}\text { Not at all } \\
\text { Important }\end{array}$ & $\begin{array}{l}\text { Very } \\
\text { Unimportant }\end{array}$ & $\begin{array}{l}\text { Neither } \\
\text { Important nor } \\
\text { Unimportant }\end{array}$ & $\begin{array}{l}\text { Very } \\
\text { Important }\end{array}$ & $\begin{array}{l}\text { Extremely } \\
\text { Important }\end{array}$ \\
\hline $\begin{array}{l}\text { 1) Have the operator's } \\
\text { pelvis level with the } \\
\text { patient's pelvis? }\end{array}$ & $\mathrm{C}$ & $\mathbb{C}$ & $\mathrm{C}$ & $\mathrm{C}$ & $\mathrm{C}$ \\
\hline $\begin{array}{l}\text { 2) Have the operator's } \\
\text { upper body up and } \\
\text { over the patient? }\end{array}$ & $\mathrm{C}$ & $\mathrm{C}$ & $\mathrm{C}$ & $\mathrm{C}$ & $\mathrm{C}$ \\
\hline $\begin{array}{l}\text { 3) Align the operator's } \\
\text { feet in a specific } \\
\text { direction relative to the } \\
\text { patient? }\end{array}$ & $\mathrm{C}$ & $\mathrm{C}$ & $\mathrm{C}$ & C & 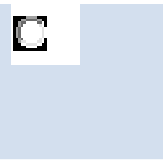 \\
\hline $\begin{array}{l}\text { 4) Use the operator's } \\
\text { hands to palpate the } \\
\text { segment? }\end{array}$ & $\mathrm{C}$ & $\mathrm{C}$ & $\mathrm{C}$ & $\mathrm{C}$ & $\mathrm{C}$ \\
\hline $\begin{array}{l}\text { 5) Use the operator's } \\
\text { forearms to maintain } \\
\text { contact and generate } \\
\text { forces? }\end{array}$ & $\mathrm{C}$ & $\mathrm{C}$ & C & C & C \\
\hline $\begin{array}{l}\text { 6) Maintain vertical } \\
\text { alignment of the } \\
\text { operator's trunk? }\end{array}$ & $\mathbb{C}$ & $\mathrm{C}$ & $\boldsymbol{C}$ & $\mathrm{C}$ & $\mathrm{C}$ \\
\hline $\begin{array}{l}\text { 7) Maintain close } \\
\text { contact between the } \\
\text { operator and the } \\
\text { patient? }\end{array}$ & $C$ & C & C & C & C \\
\hline
\end{tabular}


In terms of operator motion during the manipulation phase of a side-lying lumbar manipulation, how important is it to:

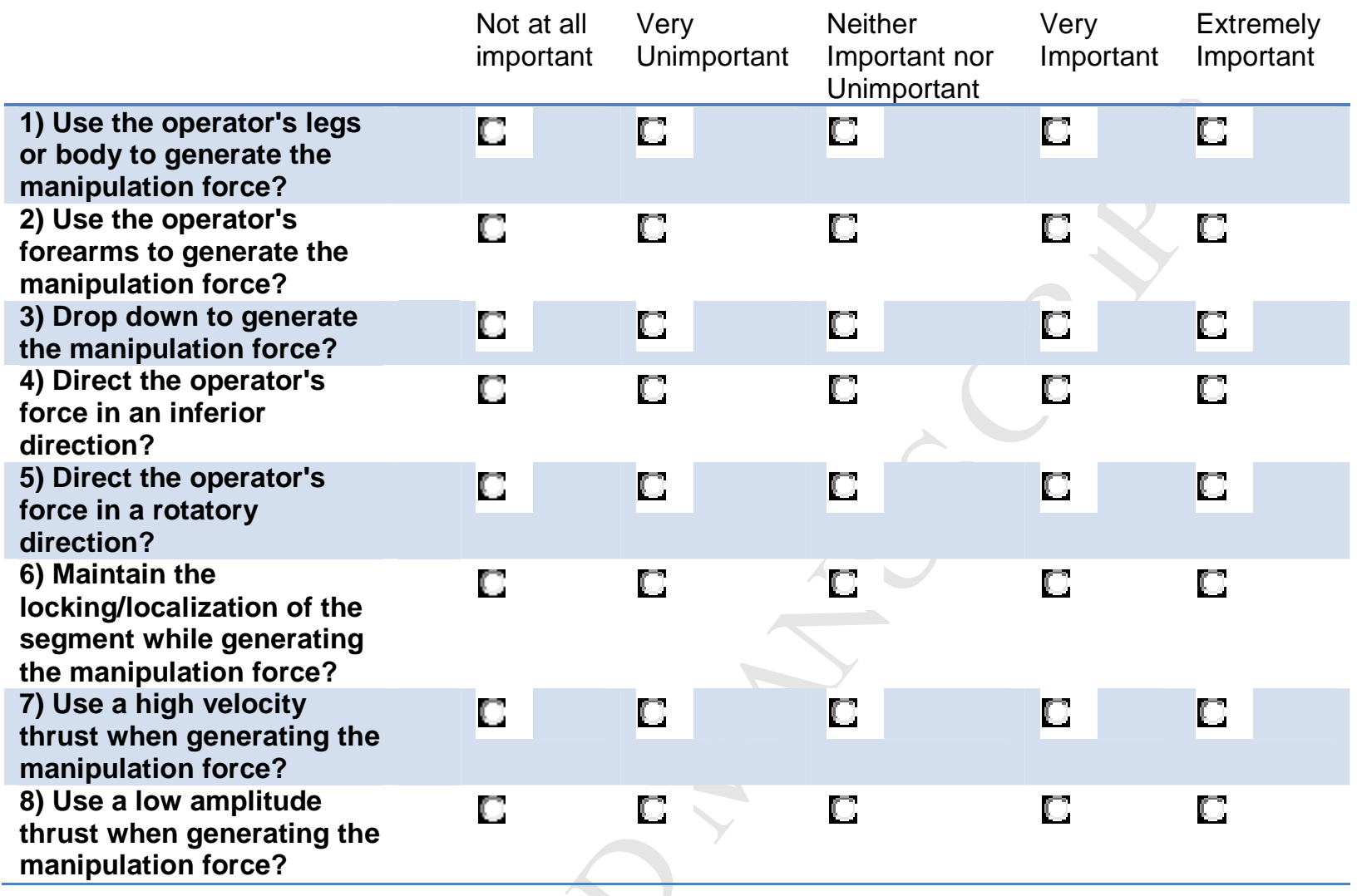


ACKNOWLEDGEMENTS

This study was funded in part by a grant from the $\mathrm{XXXX}$ 


\section{REFERENCES}

1 Chou, $\mathrm{R}$ et al. Diagnosis and treatment of low back pain: a joint clinical practice guideline from the American College of Physicians and the American Pain Society. Ann Internal Med 2007; 2:478-491.

2 Delitto A, George SV, Van Dillen L, Whitman JM, Sowa G, Shekelle P, Denninger TR, Godges JJ. Low Back Pain. Clinical practice guidelines linked to the international classification of functioning, disability, and health from the Orthopaedic Section of the American Physical Therapy Association. J Orthop Sports Phys Ther 2012; 42:A1-A57.

3 Assendelft W, Morton S, Yu E, Suttorp M, Shekelle P. Spinal manipulative therapy for low back pain. Cochrane Database Systematic Review 2004.

4 Assendelft W, Morton S, Yu E, Suttorp M, Shekelle P. Spinal manipulative therapy for low back pain. A meta-analysis of effectiveness relative to other therapies. Ann Internal Med 2003; 138:871-881.

5 McCarthy, CJ, Bialoskly, JE \& Rivett, D. Spinal Manipulation. in Grieve's Modern Musculoskeletal Physiotherapy (eds G. Jull et al.) (Elsevier Ltd, 2015).

6 Gibbons P, Tehan P. Manipulation of the Spine. Thorax and Pelvis. $3^{\text {rd }}$ edition, St Louis Missouri, Churchill Livingstone Elsevier, 2010.

$7 \quad$ Cambridge EDJ, Triano JJ, Ross JK, Abbott MS. Comparison of force development strategies of spinal manipulation used for thoracic pain. Man Ther 2012; 17:241-245.

8 Cohen E, Triano JJ, McGregor M, Papakyriakou M. Biomechanical performance of spinal manipulation therapy by newly trained vs. practicing providers: does experience transfer to unfamiliar procedures? J Manipulative Physiol Ther 1995; 18:347-352.

9 Descarreaux M, Dugas C, Raymond J, Norman MC. Kinetic analysis of spinal manipulative therapy using an instrumented manikin. J Chiropr Med 2005; 4:5360.

10 Descarreaux M, Dugas C, Lalanne K, Vincelette M, Normand MC. Learning spinal manipulation: the importance of augmented feedback relating to various kinetic parameters. Spine $J$ 2006; 6:138-145.

11 Descarreaux M, Dugas C. Learning spinal manipulation skills: assessment of biomechanical parameters in a 5-year longitudinal study. J Manipulative Physiol Ther 2010; 33:226-230.

12 Harvey MP, Wynd S, Richardson L, Dugas C, Descarreaux M. Learning spinal manipulation. A comparison of two teaching models. J Chiropr Educ 2011; 25:125-131.

13 Triano JJ, Bougle J, Rogers C, Scaringe J, Sorrels K, Skogsbergh D, Mior S. Procedural skills in spinal manipulation: do prerequisites matter? Spine J 2004; 4:557-563.

14 Triano JJ, Gissler T, Forgie M, Milwid M. Maturation of rate of high-velocity, lowamplitude force development. J Manipulative Physiol Ther 2011; 34:173-180.

15 Snodgrass SJ, Rivett DA, Robertson VJ, Stojanovski E. A comparison of cervical spine mobilization forces applied by experienced and novice physiotherapists. $J$ Orthop Sports Phys Ther 2010; 40:392-401. 
16 Hartman L. Handbook of Osteopathic Technique. 3rd edition, London UK, Chapman \& Hall 1997.

17 Olson KA. Manual Therapy of the Spine. Missouri, USA, Elsevier, 2009.

18 Maitland GD. Vertebral Manipulation. 6th edition, St Louis Missouri, Churchill Livingstone Elsevier, 2001.

19 Kaltenborn FM. The Spine: Manual Mobilization of the Joints. $5^{\text {th }}$ edition, Oslo Norway, Norli, 2009.

20 Greenman P. Principles of Manual Medicine. $2^{\text {nd }}$ edition, Baltimore MD, Lippincott Willams \& Wilkins, 1996.

21 Manipulation Education Committee of the APTA Manipulation Task Force. Manipulation Education Manual for Physical Therapist Professional Degree Programs. Alexandria VA, APTA, 2004.

22 Sizer PS, Felstehausen V, Sawyer S, Dornier L, Matthews P, Cook C. Eight critical skill sets required for manual therapy competency: a Delphi study and factor analysis of physical therapy educators of manual therapy. $J$ Allied Health 2007; 36:30-40.

23 American Physical Therapy Association. Guide to Physical Therapist Practice. Alexanadria VA, APTA, 2003.

24 Koes BW, van Tulder M,Lin, C-WC, Macedo LG, McAuley JH, Maher CG . An updated overview of clincal guidelines for the management of non-specific low back pain in primary care. Eur Spine J 2010; 19:2075-2094.

25 National Institute for Health and Care Excellence. Low back pain in adults: early mangement. http://www.nice.org.uk/guidance/cg88, 2009.

26 Notebottom JT, Little C, Boissonault W. Thrust joint manipulation curricula in first professional physical therapy education, 2012 update. J Orthop Sports Phys Ther 2015; 45:471-476.

27 Commission on Accreditation in Physical Therapy Education. Evaluative criteria for accreditation of education programs for the preparation of physical therapists. Alexandria VA, APTA, 1998.

28 Council of Canadian Physiotherapy University Programs. Entry-to-practice physiotherapy curriculum: content guidelines for Canadian university programs. HealthQuest Consulting, 2009.

29 Keeney S, Hasson F, McKenna H. Consulting the oracle: ten lessons from using the Delphi technique in nursing research. Journal of Advanced Nursing 2005; 53:205-212.

30 Dalkey NC. Studies in the quality of life; Delphi and decision making. Lanhan MD, Lexington Books, 1972.

31 Hsu CC, Sandford B. The Delphi technique: making sense of consensus. Practical Assessment, Research and Evaluation 2007; 12:1-8.

32 Krossnick JA, Presser S. Questionnaire design. Handbook of Survey Research. eds Wright JD \& Marsden PV, Emerald Group, 2010.

33 Cook C, Brismee JM, Fleming R, Sizer PS. Identifiers suggestive of clinical certical spine instability: a Delphi study of physical therapists. Phys Ther 2005; 85:895-906.

34 McCarthy CJ. Spinal manipulative thrust technique using combined movement theory. Man Ther 2001; 6:197-204. 

Edition, Churchill Livingstone, 1991.

36 Gibbons P, Tehan P. Patient positioning and spinal locking for lumbar spine rotation manipulation. Man Ther 2001; 6:130-138.

37 Stoddard A. Manual of Osteopathic Technique. London UK, Hutchinson Medical Publications, 1959.

38 Evans DW, Breen AC. A biomechanical model for mechanically efficient cavitation production during spinal manipulation: pre-thrust position and the neutral zone. J Manipulative Physiol Ther 2006; 29:72-82.

39 Pearcy MJ, Tibrewal SB. Axial rotation and alteral bending in the normal lumbar spine measured by three-dimensional radiography. Spine 1984; 9:582-587.

40 Russell P, Pearcy MJ, Unsworth A. Measurement of the range and coupled movements observed in the lumbar spine. Br J Rheumatol 1993; 32:390-497.

41 Panjabi M, Yamamoto I, Oxland T, Crisco J. How does posture affect coupling in the lumbar spine. Spine 1989; 14:1002-1011.

42 Evjenth O, Krauss J, Creighton D. Translatoric Spinal Manipulation. OPTP, 2006.

43 Beffa R, Mathews R. Does the adjustment cavitate the targeted joint? An investigation into the location of cavitation sounds. J Manipulative Physiol Ther 2004; $27: \mathrm{e} 2$.

44 Ross JK, Bereznnick DE, McGill SM. Determining cavitation location during lumbar and thoracic manipulation. Spine 2004; 29:1345-1457.

45 Cramer GD, Cambron J, Cantu JA, Dexheimer JM, Pocius JD et al. Magnetic resonance imaging of zygapophyseal joint space changes (gapping) in low back pain paitents following spinal manipulation and side posture positioning: $\mathrm{A}$ randomized controlled mechanisms trial with blinding. J Manipulative Physiol Ther 2013; 36:203-217.

$46 \quad$ Flynn, T et al. A clinical prediction rule for classifying patients with low back pain who demonstrate short-term improvement with spinal manipulation. Spine 2002; 27:2835-2843.

47 Pickar JG. Neurophysiological effects of spinal manipulation. Spine Journal 2002; 2:357-371

48 de Gelder B, de Borst AW, Watson R. The perception of emotion in body expressions. Wiley Interdiscip Rev Cogn Sci 2015; 6:149-158.

49 Groeneveld A, McKenzie ML, Williams D. Logrolling: establishing consistent practice. Orthop Nurs 2001; 20:45-49.

50 Cook C, Learman K, Showalter C. Early use of thrust manipulation versus nonthrust manipulation. A randomized clinical trial. Man Ther 2013; 18:191-198.

51 Cleland, JA et al. Comparison of the effectiveness of three manual physical therapy techniques in a subgroup of patients with low back pain who satisfy a clinical prediction rule: a randomized clinical trial. Spine 2009; 34:2720-2729.

52 Evans DW. Mechanisms and effects of spinal high-velocity, low amplitude thrust manipulation: previous theories. J Manipulative Physiol Ther 2002; 25:251-262.

53 Paris SV, Loubert PV. Foundations of Clinical Orthopaedics. Institute Press, 1990.

54 American Physical Therapy Association. APTA Manipulation Manual for Physical Therapy Professional Education Degree Programs. Alexandria VA, APTA, 2004. 
55 Murphy MK, Black N, Lamping DL, McKee CM, Sanderson CFB, Askham J, Marteau T. Consensus development methods and their use in clinical guideline development. Health Technol Assess 1998; 2.

56 Powell C. The Delphi technique: myths and realities. J Adv Nurs 2003; 41:376382.

57 Mead D, Mosely L. The use of the Delphi as a research approach. Nurse Researcher 2001; 8:4-23.

58 Wilde VE, Ford JJ, McMeeken JM. Indicators of lumbar zygapophyseal joint pain: survey of an expert panel with the Delphi Technique. Phys Ther 2007; 87:13481361.

59 Walmsley S, Rivett DA, Osmotherly PG. Adhesive capsulitis: establishing consensus on clinical identifiers for stage 1 using the Delphi Technique. Phys Ther 2009; 89:906-917.

60 Majewski-Schrage T, Evans TA, Ragan B. Development of a core-stability model: a Delphi approach. J Sport Rehabil 2014; 23:95-106.

61 Cook C, Brismee JM, Sizer PS. Subjective and objective descriptors of clinical lumbar spine instability: a Delphi study. Man Ther 2006; 11:11-21.

62 Smart, KM, Blake, C, Staines, C \& Doody, C. Clinical indicators of 'nociceptive', 'peripheral neuropathic' and 'central' mechanisms of musculoskeletal pain. A Delphi survey of expert clinicians. Man Ther 2010; 15:80-87.

63 Fritz, J. The lumbar spine: physical therapy patient management utilizing current evidence. Current Concepts of Orthopaedic Physical Therapy, Alexandria VA, 2006. 
Highlights

- Delphi study identifying key aspects of performing side-lying lumbar manipulation.

- Expert manual therapy practitioners and educators completed three-round survey.

- Identified important components of patient position before and during manipulation.

- Determined essentials of practitioner position and mechanics during manipulation.

- Consensus will help manual therapy educators better teach this technique. 